\title{
Bimbingan Teknis Peramalan Jumlah Kunjungan Pasien Dengan Tableau
}

\author{
Mieke Nurmalasari $^{1 *}$, Witri Zuama Qomarania ${ }^{2}$, Nauri Anggita Temesvari ${ }^{3}$, \\ Tria Saras Pertiwi ${ }^{4}$ \\ Program Studi Manajemen Informasi Kesehatan, Fakultas Ilmu-Ilmu Kesehatan, \\ Universitas Esa Unggul \\ Jl. Arjuna Utara No.9, Kebon Jeruk, Jakarta, Indonesia \\ *Korespondensi: mieke@esaunggul.ac.id
}

\begin{abstract}
ABSTRAK. Peramalan jumlah kunjungan pasien berguna untuk membantu manajemen dalam membuat kebijakan dan perencanaan yang efektif dan efisien. Pesatnya perkembangan teknologi menjadikan data kesehatan digital sebagai salah satu sumber big data. Perlu dilakukan peningkatan pengetahuan pada mahasiswa dan tenaga Perekan Medis dan Manajemen Informasi Kesehatan dalam menganalisis data kunjungan pasien. Metode yang digunakan dalam kegiatan ini adalah pelatihan atau bimbingan teknis yang bersifat teoritis dan praktis. Hasil dari pelatihan ini adalah peningkatan pengetahuan peserta dalam menganalisis data peramalan kunjungan pasien menggunakan software Tableau.
\end{abstract}

Kata kunci: kunjungan pasien; peramalan; analisis data; public tableau

ABSTRACT. Forecasting number of visits is useful to help management to make effective and efficient policies and plans. The rapid development of technology makes digital health data as a one of big data sources. It is necessary to increase the knowledge of student and Professional Health Information Management in analyzing the patient visit data. The method used in this activity is a training or technical guidance which is namely theoretical and practical. The result of this training is an increase in participants' knowledge in analyzing the forecasting of patient visit data using Tableau software.

Keywords: patient visit; forecasting; data analytics; public tableau

\section{PENDAHULUAN}

Perkembangan teknologi informasi menuntut semua bidang mampu bersaing secara global, termasuk bidang kesehatan. Tenaga kesehatan khususnya profesi Perekam Medis dan Manajemen Informasi Kesehatan (PMIK) mempunyai peranan yang cukup penting dalam upaya meningkatkan kualitas pelayanan kesehatan yang diberikan kepada masyarakat.

Salah satu tujuan standar profesi PMIK dalam Kepmenkes HK.01.07/MENKES/312/2020 adalah meningkatnya kemampuan profesi dalam menganalisis data dan menyajikan statistik kesehatan (Menkes RI, 2020). Sesuai dengan hal tersebut, PMIK diharapkan dapat mengolah data yang ada di pelayanan kesehatan.

Institusi Pendidikan PMIK dituntut untuk dapat memenuhi standar profesi PMIK. Keterampilan dalam pengolahan data menjadi modal peserta didik untuk bersaing di dunia kerja paska menyelesaikan pendidikannya.
Era saat ini adalah era data, salah satu sumber data besar dihasilkan dari pelayanan kesehatan. Data yang ada di pelayanan kesehatan diantaranya adalah data kunjungan pasien. Data tersebut menjadi salah satu kunci keberlangsungan suatu pelayanan kesehatan. Peramalan data kunjungan pasien diperlukan untuk memprediksi kedepannya sehingga dapat menjadi dasar dalam pembuatan suatu kebijakan. Berbagai penelitian terkait peramalan kunjungan pasien telah banyak dilakukan diantaranya oleh (Putri, 2021), (Khaldi, Afia, \& Chiheb, 2019), (Baharsyah \& Nurmalasari, 2019), (Aprilia, 2017),(Calegari et al., 2016).

Peramalan atau forecasting adalah kegiatan memprediksi suatu kejadian atau peristiwa di masa yang akan datang berdasarkan pengetahuan sebelumnya (data historis) dengan proses sistematis atau intuisi (Makridakis, C Wheelwright, \& E. McGee, 2010). Data lampau atau data historis diperlukan untuk dapat diselidiki bagaimana pola data tersebut sehingga memberikan 
gambaran untuk trend di masa yang akan datang.

Tableau mempunyai kehandalan untuk memvisualisasikan kumpulan data yang sangat besar dengan sangat mudah. Tableau memiliki antarmuka (interface) drag and drop yang mudah digunakan (Nikhat Akhtar, Nazia Tabassum, Asif Perwej, \& Yusuf Perwej, 2020). Tableau merupakan salah satu alat yang dapat digunakan untuk melakukan peramalan. (Jena, 2019) dalam artikelnya menjelaskan kemudahan dalam melakukan peramalan dan analisis prediksi dengan menggunakan Tableau.

Bimbingan teknis pengolahan data kunjungan pasien dengan menggunakan public tableau bertujuan untuk memberikan bekal kepada peserta didik untuk ke depannya. Dari workshop yang dilakukan, diharapkan dapat meningkatkan pengetahuan dan pemahaman mahasiswa manajemen informasi kesehatan dalam mengolah data kesehatan terutama data kunjungan pasien.

\section{METODE}

Kegiatan pengabdian masyarakat ini dilakukan dalam bentuk pelatihan atau bimbingan teknis dengan tema "Workshop Analisis Big Data Pelayanan Kesehatan" yang terdiri dari dua topik salah satunya adalah Analisis Peramalan Jumlah Kunjungan. Pelaksanaan kegiatan pada hari Minggu, 15 Agustus 2021, jam 08.00 18.00 secara daring melalui aplikasi zoom. Kegiatan ini terdiri dari 65 peserta yang terdiri dari mahasiswa Manajemen Informasi Kesehatan.

Tahapan kegiatan workshop yang pertama adalah pretest untuk mengetahui gambaran awal pengetahuan peserta sebelum diberi pelatihan. Tahap kedua adalah pemaparan materi terkait teori dasar peramalan dan dilanjutkan dengan demontrasi bagaimana melakukan peramalan (forecasting) dengan public tablue. Tahap ketiga adalah evaluasi peserta workshop dalam bentuk praktikum.

Bahan yang harus disiapkan selama kegiatan ini adalah peserta menyiapkan komputer atau laptop, memiliki akun dan mengunduh public tableu terlebih dahulu agar dapat mengikuti instruksi saat sesi demonstrasi. Tampilan public tableu terlihat seperti pada Gambar 1.

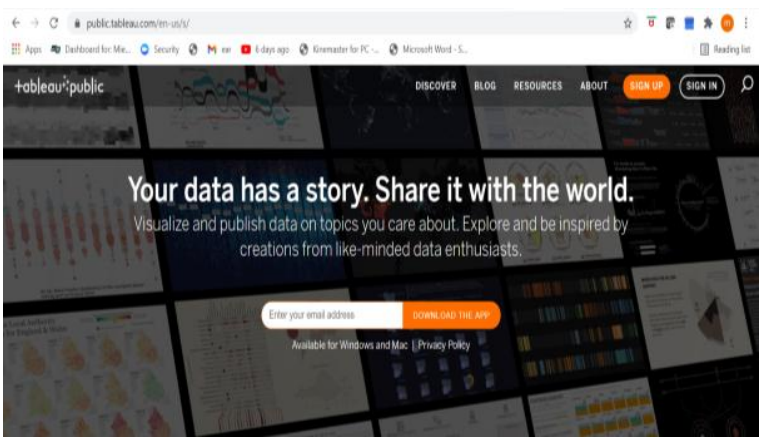

Gambar 1. Website Public Tableau Sumber: https://public.tableau.com/

\section{HASIL DAN PEMBAHASAN}

Pelaksanaan pelatihan atau workshop ini diawali dengan pretest. Ujian awal (pretest) dilakukan selama 20 menit yang diikuti oleh 65 peserta (Gambar 2). Materi pretest mencakup pengetahuan tentang Tableau, dasar-dasar eksplorasi data dan teknik peramalan (forecasting). Kegiatan dilanjutkan dengan pemaparan topik Analisis Peramalan Jumlah Kunjungan dengan public tableau selama kurang lebih 100 menit.

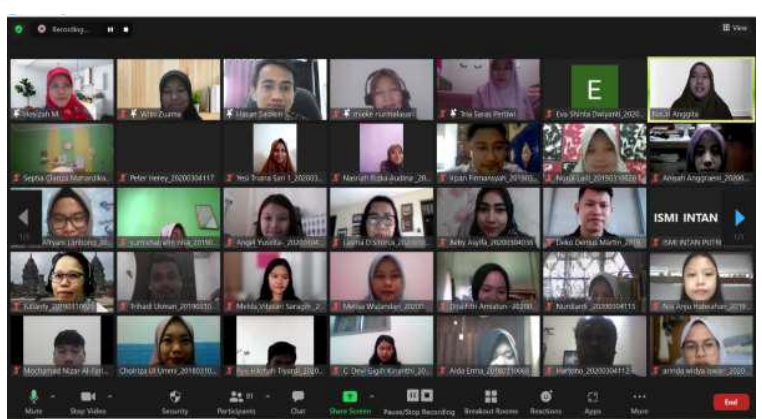

Gambar 2. Peserta Pelatihan

Outline atau garis besar materi yang disampaikan adalah pendahuluan, penyiapan data (data preparation), eksplorasi data (data exploration), prosedur peramalan (forecasting) dengan tableau, evaluasi kualitas model peramalan dengan tableau dan terakhir adalah membuat dashboard.

Pada bagian pendahuluan dijelaskan tentang teori, konsep dasar peramalan dan manfaatnya. Selain itu juga dijelaskan tentang jenis teknik peramalan. Teknik peramalan (forecasting) ada beberapa macam diantaranya adalah Auto Regression (AR), Moving Average (MA), Auto Regressive Integrated Moving Average 
(ARIMA), Exponential Smoothing, dan lainnya. Pemilihan metode peramalan berdasarkan pola yang ada dalam data. Pola data dibagi menjadi beberapa komponen yaitu (1) Trend adalah suatu kecenderungan umum (general tendency) dari suatu data berkala (cenderung naik/turun). (2) Seasonal yaitu komponen dalam time series yang menunjukkan reguler fluktuasi berdasarkan musim (misalnya setiap bulan/kuartal/tahun). (3) Cycle yaitu data menunjukkan naik dan turun yang jangka waktu tidak tetap/reguler. Panjang rata-rata siklus lebih panjang dari panjang pola musiman. (4) Irregular component merupakan komponen yang tidak stasioner (Makridakis et al., 2010).

Peramalan di Tableau menggunakan teknik yang dikenal sebagai pemulusan eksponensial (Exponential Smoothing). Peramalan ini mencoba menemukan pola reguler yang dapat dilanjutkan ke masa depan dengan cara data terbaru (recent data) diberi bobot lebih tinggi dibandingkan data yang lalu atau sebelumnya. Exponential Smoothing menggunakan rata-rata tertimbang dari pengamatan masa lalu untuk meramalkan nilai-nilai baru (Tableau, n.d.).

\section{Metode Exponential Smoothing} menggabungkan komponen Error, Trend, dan Seasonal dalam perhitungan pemulusan (smoothing). Bentuk umum dari persamaan memiliki dekomposisi aditif: $\mathrm{Y}_{\mathrm{t}}=\mathrm{T}_{\mathrm{t}}+\mathrm{S}_{\mathrm{t}}+\mathrm{E}_{\mathrm{t}}$ (1), dimana komponen tren (T), musiman ( $\mathrm{S}$ ) dan error (E) ditambahkan bersama untuk menghasilkan deret yang diamati. Bentuk umum untuk persamaan memiliki dekomposisi multiplikatif: $Y_{t}=T_{t} \cdot S_{t} \cdot E_{t}(2)$, dimana komponen tren (T), musiman (S) dan error (E) dikalikan bersama untuk menghasilkan deret yang diamati.

Materi berikutnya adalah persiapan data. Peserta diajarkan bagaimana menyiapkan data untuk dianalisis. Sumber data ada di "data source", kemudian "sheet" sebagai tempat melakukan analisis (worksheet). Peserta dilatih memeriksa tipe data sudah sesuai atau tidak sebelum dianalisis lebih lanjut. Tahap selanjutnya adalah eksplorasi data, bagian ini penting dilakukan di awal untuk memperoleh gambaran pola data yang akan diramalkan. Diagram garis (line graph) dapat digunakan pada tahap eksplorasi data. Line Graph berguna untuk memberikan informasi bagaimana sesuatu berubah dari waktu ke waktu. Apakah data kunjungan pasien mengalami perubahan dari waktu ke waktu?

Materi prosedur peramalan di public tableau diberikan dengan memberikan contoh atau mendemonstrasikan langsung tahapantahapannya dan peserta mengikuti instruksi. Narasumber memberikan tiga cara dalam melakukan peramalan di tableau. Cara pertama. Klik kanan pada view, kemudian pilih Forecast dan Show Forecast. Cara kedua melalui menu "Analysis" yaitu Analysis > Forecast > Show Forecast dan cara ketiga menggunakan menu "Analytics", kemudian drag "Forecast" ke arah view. Ringkasan materi ditampilkann pada Gambar 3.

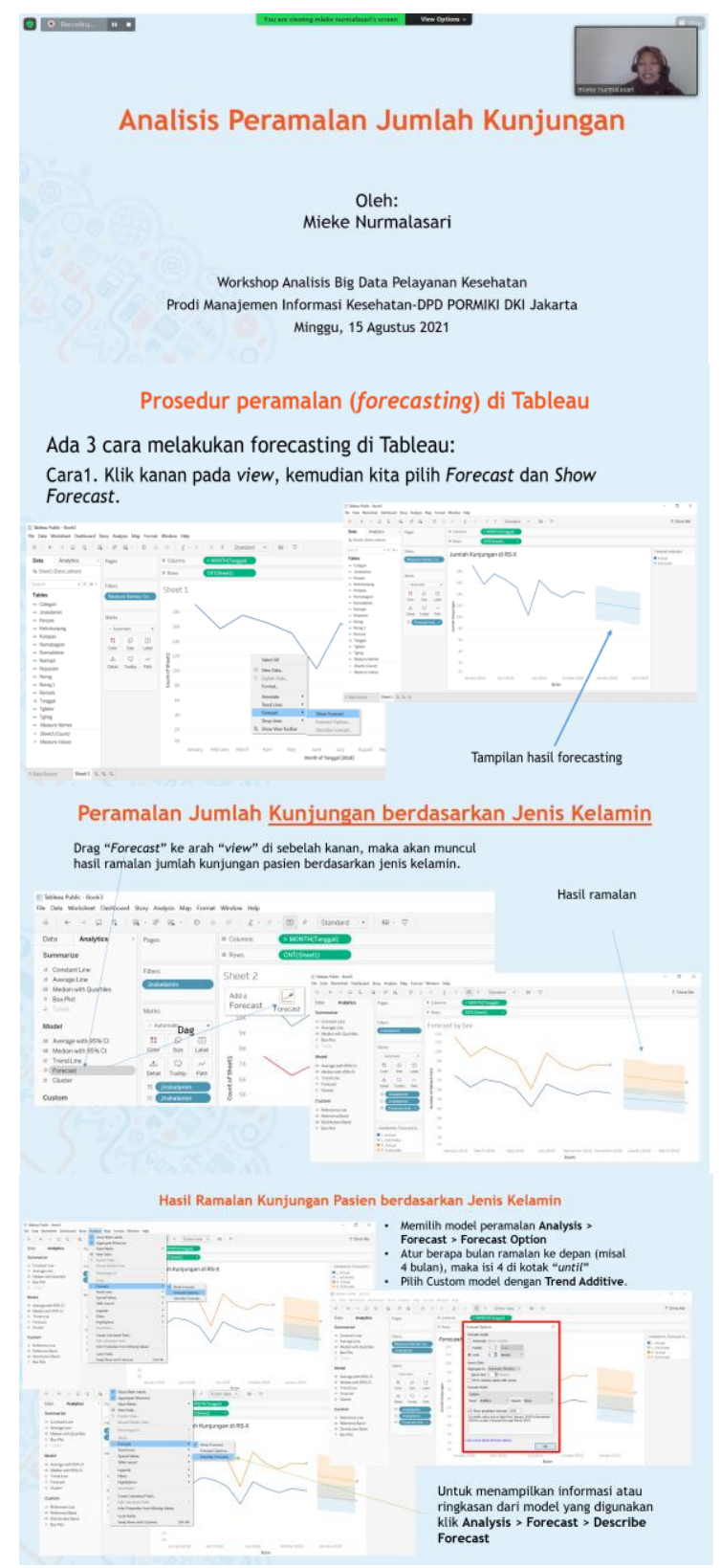




\section{Gambar 3. Penyampaian Materi Peramalan dengan Public Tableau.}

Materi berikutnya adalah Evaluasi Kualitas Model Peramalan di Tableau. Kualitas model peramalan dilihat dari menu Analysis $>$ Forecast $>$ Describe Forecast. Kotak dialog Describe Forecast mempunyai dua tab yaitu Summary tab dan Models tab. Summary tab menjelaskan model perkiraan yang dibuat Tableau, serta pola umum yang ditemukan Tableau dalam data.

Model tab memberikan informasi lengkap tentang nilai koefisien pemulusan exponential smoothing model, selain itu juga memberikan informasi statistik kualitas model peramalan (Gambar 4). Ukuran kualitas model peramalan dilihat dari nilai "Root Mean Square Error (RMSE), Mean Absolute Error (MAE), Mean Absolute Scaled Error (MASE), Mean Absolute Percentage Error (MAPE) dan Akaike Information Criterion (AIC)".

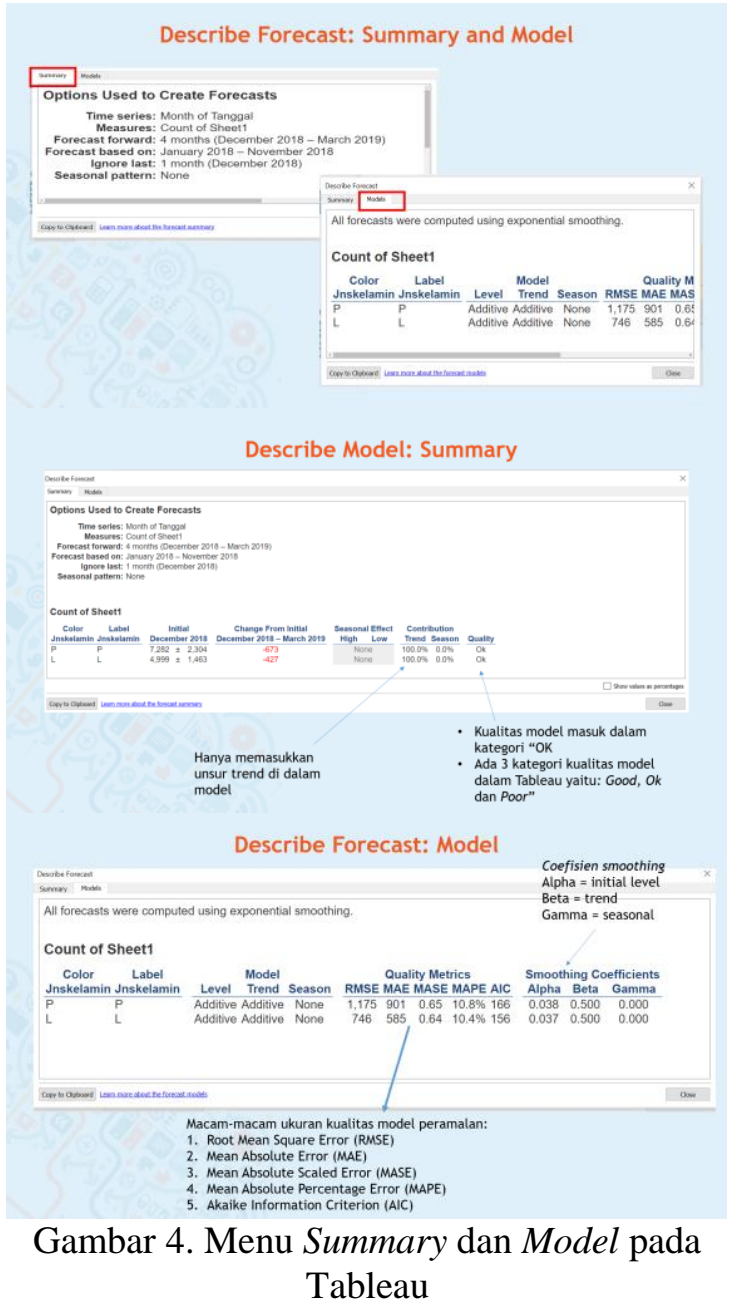

Tahap terakhir adalah materi membuat dashboard di public tableau untuk menampilkan semua grafik dan hasil peramalan berdasarkan model peramalan. Dashboard mempermudah untuk membaca hasil pengolahan dan analisis data secara menyeluruh, sehingga memudahkan dalam pengambilan keputusan.

Sesi evaluasi (Gambar 5) dilaksanakan setelah istirahat siang terlebih dahulu. Evaluasi ini bertujuan mengetahui sejauh mana pemahaman peserta terhadap materi yang telah diberikan. Proses evaluasi dilakukan dengan memberikan pertanyaan untuk diselesaikan. Peserta diminta melakukan analisis peramalan sampai dengan menampilkan dalam bentuk dashboard seperti yang sudah diajarkan oleh pemateri. Proses evaluasi berlangsung selama kurang lebih 4 jam. Peserta mengirimkan hasil evaluasi berupa link (URL) tempat menyimpan hasil kerja dari masing-masing akun di public tableau serta mempresentasikan hasil analisanya.

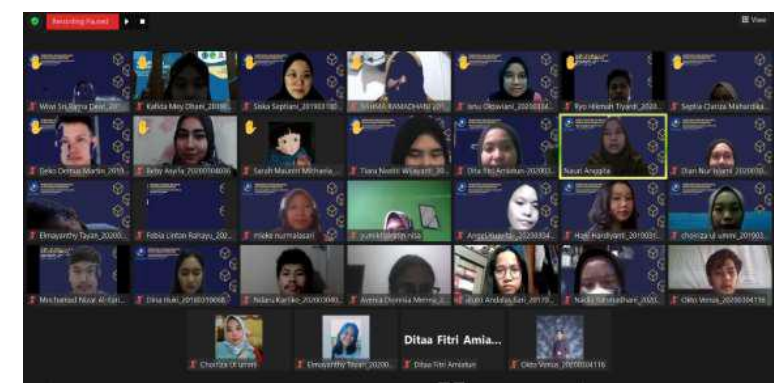

Gambar 5. Ruang Evaluasi Peserta

Secara keseluruhan kegiatan pelatihan ini berjalan lancar. Sebagian besar peserta dapat mengikuti materi yang disampaikan. Peserta berpartisipasi aktif selama kegiatan berlangsung dan dapat membuat peramalan (forecasting) data kunjungan pasien berdasarkan beberapa kategori seperti cara berkunjung ke fasilitas kesehatan (datang sendiri, dari puskesmas, lewat telepon, dari rumah sakit atau fasilitas kesehatan lainnya), cara bayar (BPJS, Non BPJS), dan lainnya. Sebagian besar peserta berhasil membuat dashboard untuk menampilkannya grafik dan hasil peramalan. Pelatihan atau bimbingan teknis ini dapat meningkatkan pengetahuan dan kemampuan peserta dalam mengolah data kunjugan. Salah satu indikator keberhasilan ini adalah adanya peningkatan nilai rata-rata, saat 
pretest sebesar 52 dan setelah diberi pelatihan nilai rata-rata peserta meningkat menjadi 73 .

\section{SIMPULAN}

Kegiatan pelatihan ini memberikan peningkatan pengetahuan bagi peserta dalam mengolah data kunjungan pasien dari mulai tahap eksplorasi, peramalan dan evaluasi model peramalan dengan menggunakan public tableau.

\section{UCAPAN TERIMAKASIH}

Terimakasih penulis sampaikan kepada Program Studi Manajemen Informasi Kesehatan, Universitas Esa Unggul dan DPP PORMIKI Jakarta untuk kerjasamanya sehingga kegiatan ini dapat terselenggara dengan baik.

\section{DAFTAR PUSTAKA}

Aprilia, D. (2017). Penerapan Metode Forecast Exponential Smoothing pada Jumlah Pasien Puskesmas. Jurnal Biometrika Dan Kependudukan, 5(2), 146. https://doi.org/10.20473/jbk.v5i2.2016.1 46-156

Baharsyah, N., \& Nurmalasari, M. (2019). Patient Visit Forecasting at Emergency Department using Autoregressive Integrated Moving Average (ARIMA) and Exponential Smoothing Method in RSUD Kembangan. Proceedings of the 1st International Conference on Health, 234-239.

https://doi.org/10.5220/00095903023402 39

Calegari, R., Fogliatto, F. S., Lucini, F. R., Neyeloff, J., Kuchenbecker, R. S., \& Schaan, B. D. (2016). Forecasting Daily Volume and Acuity of Patients in the
Emergency Department. Computational and Mathematical Methods in Medicine, 2016.

https://doi.org/10.1155/2016/3863268

Jena, B. (2019). An Approach for Forecast Prediction in Data Analytics Field by Tableau Software. International Journal of Information Engineering and Electronic Business, 11(1), 19-26. https://doi.org/10.5815/ijieeb.2019.01.03

Khaldi, R., Afia, A. El, \& Chiheb, R. (2019). Forecasting of weekly patient visits to emergency department: Real case study. Procedia Computer Science, 148, 532541.

https://doi.org/10.1016/j.procs.2019.01.0 26

Makridakis, S., C Wheelwright, S., \& E. McGee, V. (2010). Metode dan Aplikasi Peramalan Jilid 1. Binarupa Aksara.

Menkes RI. Kepmenkes Nomor: HK.01.07/MENKES/312/2020 Tentang Standar Profesi Perekam Medis dan Informasi Kesehatan., (2020).

Nikhat Akhtar, Nazia Tabassum, Asif Perwej, \& Yusuf Perwej. (2020). Data analytics and visualization using Tableau utilitarian for COVID-19 (Coronavirus). Global Journal of Engineering and Technology Advances, 3(2), 028-050. https://doi.org/10.30574/gjeta.2020.3.2.0 029

Putri, M. T. (2021). Visualization of Forecasting Number of Patients Visiting in Pratama Clinic Using Arima Method. Intelmatics, $\quad 1(1), \quad 16-19$. https://doi.org/10.25105/itm.v1i1.7427 